\section{Absentee ratio for boost-phase ASATs}

SIR-For satellites at an altitude of $483 \mathrm{~km}$, firing rockets with $6 \mathrm{~km} \mathrm{~s}^{-1}$ velocity, at boosters that burn for $300 \mathrm{~s}$, the absentee ratio is 64 , and it increases rapidly for shorter burn times.

Both supporters and opponents of the Strategic Defense Initiative (SDI) agree that an efficient boost-phase defence is critical. The main reasons are that the boosters are easily acquired targets and that destroying a booster destroys all its warheads and decoys. But if the satellites have altitudes of only a few hundred miles, they have a large absentee ratio, defined as the number of satellites that have to be deployed so that one satellite, on the average, is in range of the target at all times.

I have calculated the absentee ratio using numerical values from ref. 1 , which gives the most favourable parameters for the defence that I have seen. They have the satellites at an altitude of $483 \mathrm{~km}$ (300 miles), firing rockets with 20 -g thrust to attain a velocity of $6 \mathrm{~km} \mathrm{~s}^{-1}$. Using these values, the value of the absentee ratio, $a$, is 64 , for a booster burn time, $t_{0}$, of $300 \mathrm{~s}$; $a=206$ for $t_{0}=180 \mathrm{~s}$ (the boost phase of the MX missile).

The absentee ratio for satellites uniformly distributed in solid-angle (as seen from the centre of the Earth) is calculated below. If the satellite inclinations are optimized for a clustered launch at latitude $55^{\circ} \mathrm{N}$, the absentee ratios are reduced by a concentration factor, $y$, which has values around two to three.

As seen from the centre of the Earth, a satellite at an altitude $h$ firing rockets with a range $r=v t_{0}$, has in range all points within a solid angle $\Delta \Omega$, where

$$
\Delta \Omega=2 \pi(1-\cos \theta)
$$

where $\theta$ is the angle between the vectors from the centre of the Earth to the satellite and to the target. The area accessible to the satellite is $\Delta A=R^{2} \Delta \Omega$ (where $R$ is the radius of the Earth), and the absentee ratio is $a=A / \Delta A=2 /(1-\cos \theta)$, where $A=4 \pi R^{2}$ is the total area of the Earth.

If it is assumed that the intercept occurs above the atmosphere (about $100 \mathrm{~km}$ ) but below the burn-out altitude $(200 \mathrm{~km}$ for the MX), say at an altitude, $h_{0}$, of $150 \mathrm{~km}$, then the absentee ratio may be written as $a_{1}=4\left(R+h_{0}\right)(R+h) /\left[r_{1}^{2}-\left(h-h_{0}\right)^{2}\right]$

The average velocity during the first $30 \mathrm{~s}$, while the rocket is accelerating to $6 \mathrm{~km} \mathrm{~s}^{-1}$, is $3 \mathrm{~km} \mathrm{~s}^{-1}$. To take that into account, subtract $15 \mathrm{~s}$ from the burn-time so that $r_{1}=$ $v\left(t_{0}-15 \mathrm{~s}\right)=v t_{1}$.

I have used equation (2) to calculate $a_{1}$ in Table 1. The next row gives the concentration factor, $y$, by which the absentee ratio should be divided, if the satellites

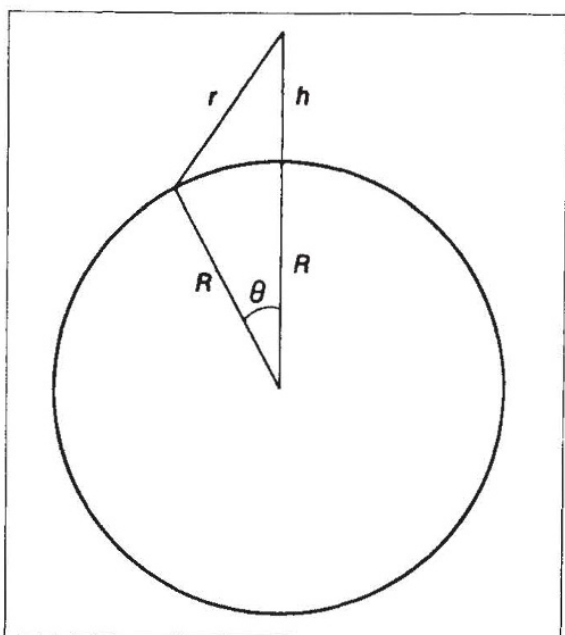

Fig. 1 Looking perpendicular to the plane containing the satellite (at a distance $(R+h)$ from the centre of the Earth) and the target (on the surface of the Earth) a distance $r$ from the satellite.

are optimized for boosters launched from $55^{\circ} \mathrm{N}$. This was calculated from a derivation by Garwin ${ }^{2}$, which, for $a \gg 1$, gives $y=2 a^{1 / 4} / \pi[\sin (2 I)]^{1 / 2}$, where $I$ is the launch latitude.

Table 1 Absentee ratio and correction factors for various values of $t_{0}$ (the booster burn time in seconds)

\begin{tabular}{ccc}
\hline$t_{0}$ & $a_{1}$ & $y$ \\
120 & 625 & 3.28 \\
180 & 206 & 2.49 \\
240 & 104 & 2.17 \\
300 & 64 & 2.08 \\
\hline
\end{tabular}

The total number of satellites required for boost-phase defence is dictated by the target site with the most boosters and antisatellite weapons (ASATs). If that site has 200 boosters and ASATs, and if, as in the Marshall Report, each satellite carries $10 \mathrm{KKVs}$ (rockets), each of which makes a kill, then the busiest site requires 20 satellites. If we neglect the submarinelaunched missiles and optimize for a launch from latitude $55^{\circ}$, the total number of satellites, $N$, is given by $N=20 \times a / y=$ 615 for $t_{0}=300 \mathrm{~s}$ and $N=1,655$ for $t_{0}=180 \mathrm{~s}$. Furthermore, for every additional 10 boosters or ASATs deployed at that site, we would have to deploy $a / y$ additional satellites; 31 additional satellites for $t_{0}=300$ and 83 additional satellites for $t_{0}=180$. Finally, if we allow for missiles launched from widely different latitudes (for example, submarinelaunched missiles), we lose the divisor ' $y$ '.

Harvard-Smithsonian

Center for Astrophysics, 60 Garden Street, Cambridge, Massachusetts 02133, USA

1. Rep. of the Technical Panel on Missile Defense in the 1990s (George C. Marshall Institute, Washington DC. 1987). . Garwin, R. L. Nature 315. 286 (1985).

\section{Isotopically depleted rainfall and El Niño}

SIR-The El Niño/Southern Oscillation (ENSO) phenomenon is the single most prominent signal of interannual climatic variability, ocurring every two to seven years when the upwelling of cold water off the coast of Peru is inhibited by weaker than normal trade winds ${ }^{1.2}$. El Niño disturbances are accompanied by catastrophic rains in South America, and widespread drought in Australia and Africa ${ }^{3}$, the obvious human consequences of which have meant that a large effort has been mounted in recent years to understand, and ultimately predict, the phenomenon. Here I report historical data that suggest that El Niño events are associated with stable isotope depletion of the rainfalls in the equatorial Pacific.

Canton Island lies on the margin of the equatorial dry zone $\left(2.77^{\circ} \mathrm{S}, 171^{\circ} \mathrm{W}\right.$, mean annual precipitation $748 \mathrm{~mm}$; ref. 4 ), in the central west Pacific Ocean. Most of the island's total rainfall is associated with the heavy and widespread rains that fall in the central Pacific during El Niño events ${ }^{5}$. Therefore the island is sensitively placed to record variations in the stableisotope composition of precipitation at such times.

Isotopic data is available for Canton Island ${ }^{4.6 .7}$ for the period early 1962 to mid1966 , which coincidentally covers two El Niño events. Examination of the data reveals a marked depletion in the heavy isotopes of oxygen (and hydrogen) in rainfall associated with ENSO disturbances, with a change from 'normal' $\delta^{18} \mathrm{O}$ values of -3 to +2 per mil, to depleted values of -6 to -8 per mil. As shown in the figure, allowing for a slight time lag, the isotopic data are strongly correlated with fluctuations in both the Southern Oscillation Index (the normalized sea-level pressure difference between Darwin and Tahiti ${ }^{2}$ ) and Canton Island sea surface temperature.

Similar depletions in the abundance of the heavy isotopes with increasing rainfall are well documented from tropical island stations (the so-called amount effect ${ }^{9}$ ) and are commonly associated with monsoon rainfall and movements of the intertropical convergence zone $\mathrm{e}^{10}$. If the isotopic variations at Canton Island were simply due to the effect of the monsoons, then the variations would be an annual phenomenon, as in precipitation during the same period at other Pacific stations, such as Apia, Samoa (see figure).

Under normal conditions, monsoon rainfall does not enter the Canton Island area and the little rain that does fall is derived from the trade winds with an isotopic composition that is similar to that which falls year round at, for example, 